\title{
Study on Evaluation and Control Method for Thermal Environment of a Residential Site Planning Based on CTTC Model
}

\author{
Haoyan Liang ${ }^{1}$, Qinglin Meng ${ }^{1}$, Langjie He ${ }^{2}$, Peng Ren ${ }^{1}$, Xiaohui Li ${ }^{2}$ \\ ${ }^{1}$ South China University of Technology, Guangdong, Guangzhou,510641, China. \\ ${ }^{2}$ Guangzhou Urban Planning Design Survey Research Institute, Guangdong, Guangzhou,510060, \\ China.
}

Keywords: CTTC; Thermal environment; Simulation; Evaluation; Control method.

\begin{abstract}
Six scenarios alternative which is for a residential area in Guangzhou are set up from building layout, building height, open Ground-floor space, greening and tree rate aspects, and six schemes are simulated based on the CTTC model, in order to analyzing the influence of different planning and design methods on the thermal environment. The analysis results show that: firstly, the methods of building open Ground-floor space, increasing the green rate and the number of trees are the most effectively for improving the thermal environment of the residential area; secondly, the effectiveness of design strategy for reducing heat island as follows: increasing arbor number and ratio $>$ increasing green space rate $>$ building on stilt $>$ building height layout of south low and north high $>$ point-high building layout; thirdly, although the tower building layout can improve the wind environment in the residential area, the increase of the incidence of solar radiation will increase the intensity of the heat island. The thermal environment of the residential area has been effectively improved through making 3 aspects of building layout and design, greening design, paving and sun shading design, and 10 detailed design strategies for improving thermal environment.
\end{abstract}

\section{Introduction}

Starting from the 1980s, China has been facing the gradual acceleration of urbanization, which is extensively accompanied by various problems in urban ecological environment. Among them, urban heat island has changed urban heat environment and affected the regional climate and air quality as well as the distribution and behaviors of urban living things and a variety of urban ecological processes, so it becomes one of the important reasons for a series of issues regarding ecological environment. For this reason, it is urgent to carry out thermal environment evaluation of schemes from the perspective of urban planning at the beginning of urban construction and utilize the planning regulation for control over possible heat island. At present, urban thermal environment evaluation mainly relies on such model as statistical model, energy balance model, numerical model, analytical model and physical model, which are classified into mathematical models and laboratory simulation models. Among them, laboratory simulation models include large-scale regional meteorological models represented by WRF, MM5 and RBLM, and medium/small-scale models represented by CFD. Numerical models are mainly represented by Summers model, CTTC model and urban canopy model.

In 1990, H.N. Swaid and Milo E. Hoffman developed the cluster thermal time constant (CTTC) model for predicting the variations of temperature in the urban canopy layer and tested it in Jerusalem. Lin B.R., Shu L.F., Chen J.M., Zhang Y.F. Liu D.L., Sun Y.X. and other Chinese scholars have performed the detailed study and improvement of CTTC model. In general, the studies on CTTC model often focus on theories, but rarely pay attention to the practical planning. Taking a residential community in Guangzhou as an example, this paper creates the schemes for six scenarios from the perspectives of building layout, building height and greening, etc., and utilizes the CTTC model to simulate the thermal environment for such schemes and analyze the influence of different planning designs on thermal environment. On this basis, design strategies are developed for thermal environment regulation in a targeted manner, so as to optimize the planning design. 


\section{Research Object and Methods}

\subsection{Research Object}

The planned residential community is located in Guangzhou City, Guangdong Province with a land area of around 9.99ha. With a South Asia tropical monsoon marine climate, Guangzhou City is warm and humid, and has long summer time and short winter period. In May-September, Guangzhou has the monthly average temperature higher than $26^{\circ} \mathrm{C}$, and the monthly average absolute humidity higher than $15 \mathrm{~g} / \mathrm{kg}$. The percentage of calm wind is $21.08 \%$, and the average wind speed ranges $1.5 \sim 2.4 \mathrm{~m} / \mathrm{s}$. The southeast wind prevails. Hence, Guangzhou faces the stuffiest weather in these months.

\subsection{CTTC Model and Calculation Method}

CTTC model is constructed on the basis of heat balance to calculate the variation of air temperature in a local urban environment with external heat disturbances by using the thermal response time of buildings. The calculation method is as follows:

$$
\begin{array}{r}
\mathrm{t}_{a}(\tau)=\bar{t}_{\text {tmd }}+\Delta t_{\text {sol }}(\tau)-\Delta t_{l w}(\tau)-\Delta t_{\text {lat }}(\tau) \\
\Delta t_{\text {sol }}(\tau)=\sum_{\mathrm{i}=0}^{i=\tau} \frac{\rho}{\alpha(\tau)} \cdot \Delta I_{S R}(i) \cdot\left[1-\exp \left(\frac{i-\tau}{C T T C}\right)\right] \\
\Delta \mathrm{t}_{l w}(\tau)=\sigma\left[t_{a \cdot T M D}(\tau)+273.15\right]^{4}\left[1-B_{r}(\tau)\right] \frac{S V F}{\alpha(\tau)} \\
\Delta \mathrm{t}_{\text {lat }}(\tau)=\frac{\mathrm{I}_{\text {lat }}(\tau)}{1.005 H \cdot\left(-0.0039 t_{t m d}(\tau)+1.2822\right)+\alpha(\tau)}
\end{array}
$$

In these equations, $\mathrm{t}_{a}(\tau)$ : residential community temperature $\left({ }^{\circ} \mathrm{C}\right)$ at the time $\tau ; \bar{t}_{\text {tmd }}$ : average temperature on typical weather days $\left({ }^{\circ} \mathrm{C}\right) ; \Delta t_{s o l}(\tau)$ : temperature rise caused by solar radiation $\left({ }^{\circ} \mathrm{C}\right)$; $\Delta t_{l w}(\tau)$ : temperature drop resulting from long-wave radiation $\left({ }^{\circ} \mathrm{C}\right) ; \Delta t_{\text {lat }}(\tau)$ : temperature drop resulting from evaporation heat transfer $\left({ }^{\circ} \mathrm{C}\right) ; \rho$ : average solar radiation absorption coefficient; $\alpha(\tau)$ : integrated heat transfer coefficient $\left(\mathrm{w} / \mathrm{m}^{2} \cdot \mathrm{K}\right) ; \Delta I_{S R}(i)$ : solar irradiance $\mathrm{step}\left(\mathrm{w} / \mathrm{m}^{2}\right)$; CTTC: cluster thermal time constant (h); $\sigma$ : Stefan-Boltzmann constant, taking $5.67 \times 10^{-8} \mathrm{~W} / \mathrm{m}^{2} \cdot \mathrm{k} ; B_{r}(\tau)$ : Prandtl number; SVF: average sky view factor of residential community; $\mathrm{I}_{\text {lat }}(\tau)$ : evapotranspiration heat flux $\left(\mathrm{w} / \mathrm{m}^{2}\right) ; \mathrm{H}$ : affected height of evapotranspiration, taking $100 \mathrm{~m}$.

$$
\begin{gathered}
\rho=\frac{S_{r} \rho_{r}+S_{s} \rho_{s}+S_{g} \rho_{g}+S_{w} \rho_{w}}{S_{r}+S_{s}+S_{g}+S_{w}} \\
\alpha(\tau)=10.9+4.1 v(\tau) \\
\Delta I_{S R}(\tau)=I_{S R}(\tau+1)-I_{S R}(\tau) \\
\mathrm{CTTC}=\left(1-\frac{S_{b}+S_{t}}{S}\right) C_{d}+\frac{S_{b l}}{S} C_{b}+\frac{S_{t}}{S} C_{t} \\
B_{r}(\tau)=0.605+0.518 \sqrt{\frac{\mathrm{P}_{t m d}(\tau)}{1000}} \\
\mathrm{I}_{l a t}(\tau)=\left[S_{w} m_{w}(\tau)+S_{g} m_{g}(\tau)+S_{c} m_{c}(\tau)+S_{d} m_{d}(\tau)\right] \cdot \frac{L(\tau)}{3.6 S} \\
\mathrm{~L}(\tau)=2491.146-2.302 \mathrm{t}_{\mathrm{tmd}}(\tau)
\end{gathered}
$$

In these equations, $\mathrm{S}$ : total area of residential community $\left(\mathrm{m}^{2}\right) ; S_{r}, S_{s}, S_{g}, S_{w}, S_{c}, S_{d}, S_{t}$, and $S_{b}$ : area of road, plaza, greening, waters, permeable ground, rooftop greening, tree projection, and building base; $S_{b 1}$ : area of building elevation shorter than $18 \mathrm{~m} ; \rho_{r}, \rho_{s}, \rho_{g}$, and $\rho_{w}$ : solar radiation absorption coefficient of road, plaza, greening and waters (Table 2 ); $m_{w}(\tau), m_{g}(\tau), m_{c}(\tau)$, and $m_{d}(\tau)$ : average evapotranspiration of water surface, green space, permeable ground, and rooftop 
greening $\left(\mathrm{kg} / \mathrm{m}^{2} \cdot \mathrm{h}\right) ; C_{d}, C_{b}$, and $C_{t}$ : thermal time constant of open space, buildings and trees in residential community $(\mathrm{h})$, taking $8 \mathrm{~h}, 6 \mathrm{~h}$, and $12 \mathrm{~h}$ respectively; $v(\tau)$ : average wind speed of residential area $(\mathrm{m} / \mathrm{s}) ; I_{S R}(\tau)$ : solar irradiance; $L(\tau)$ : evapotranspiration heat flux $\left(\mathrm{w} / \mathrm{m}^{2}\right) ; \mathrm{P}_{t m d}(\tau)$ : hourly water vapor pressure of typical weather day $(\mathrm{KPa}) ; \mathrm{h}_{t m d}(\tau)$ : hourly relative humidity of typical weather day $(\%) ; \mathrm{t}_{t m d}(\tau)$ : hourly temperature of typical weather day $\left({ }^{\circ} \mathrm{C}\right)($ Table 1$)$.

Table 1. Meteorological parameters of Guangzhou's typical weather day in summer

\begin{tabular}{|c|c|c|c|c|c|}
\hline $\begin{array}{c}\text { Beijing } \\
\text { Time } \\
\end{array}$ & $\begin{array}{c}\text { Dry Bulb } \\
\text { Temperature }\left({ }^{\circ} \mathrm{C}\right) \\
\end{array}$ & $\begin{array}{c}\text { Relative } \\
\text { Humidity (\%) } \\
\end{array}$ & $\begin{array}{l}\text { Horizontal Global } \\
\text { Radiation }\left(\mathbf{W} / \mathbf{m}^{2}\right) \\
\end{array}$ & $\begin{array}{l}\text { Horizontal Diffuse } \\
\text { Radiation }\left(\mathbf{W} / \mathbf{m}^{2}\right) \\
\end{array}$ & $\begin{array}{c}\begin{array}{c}\text { Wind Speed } \\
(\mathrm{m} / \mathrm{s})\end{array} \\
\end{array}$ \\
\hline 0 & 26.2 & 89 & 0 & 0 & 0.3 \\
\hline 1 & 26.1 & 89 & 0 & 0 & 0.0 \\
\hline 2 & 26.1 & 88 & 0 & 0 & 0.3 \\
\hline 3 & 26.1 & 87 & 0 & 0 & 0.7 \\
\hline 4 & 26.3 & 85 & 0 & 0 & 1.0 \\
\hline 5 & 26.6 & 82 & 0 & 0 & 1.3 \\
\hline 6 & 27.0 & 80 & 38.89 & 33.33 & 1.7 \\
\hline 7 & 27.5 & 77 & 122.22 & 86.11 & 2.0 \\
\hline 8 & 28.2 & 74 & 216.67 & 133.33 & 2.0 \\
\hline 9 & 29.0 & 71 & 308.33 & 172.22 & 2.0 \\
\hline 10 & 29.7 & 68 & 388.89 & 202.78 & 2.0 \\
\hline 11 & 30.4 & 66 & 444.44 & 225.00 & 2.0 \\
\hline 12 & 30.9 & 65 & 466.67 & 233.33 & 2.0 \\
\hline 13 & 31.1 & 64 & 450.00 & 227.78 & 2.0 \\
\hline 14 & 31.0 & 65 & 397.22 & 208.33 & 2.0 \\
\hline 15 & 30.7 & 66 & 319.44 & 175.00 & 2.0 \\
\hline 16 & 30.1 & 68 & 225.00 & 133.33 & 2.0 \\
\hline 17 & 29.4 & 71 & 130.56 & 83.33 & 2.0 \\
\hline 18 & 28.8 & 75 & 47.22 & 33.33 & 2.0 \\
\hline 19 & 28.1 & 78 & 0 & 0 & 2.0 \\
\hline 20 & 27.6 & 81 & 0 & 0 & 1.7 \\
\hline 21 & 27.1 & 85 & 0 & 0 & 1.3 \\
\hline 22 & 26.7 & 87 & 0 & 0 & 1.0 \\
\hline 23 & 26.4 & 90 & 0 & 0 & 0.7 \\
\hline $\begin{array}{l}\text { Average } \\
\text { Daily }\end{array}$ & 28.2 & 77 & 273.50 & 149.79 & 1.5 \\
\hline
\end{tabular}

Table 2. Solar radiation absorption coefficient of typical ground surface

\begin{tabular}{|c|c|c|}
\hline $\begin{array}{c}\text { Type of Ground } \\
\text { Surface }\end{array}$ & Material of Ground Surface & $\begin{array}{c}\text { Solar Radiation Absorption } \\
\text { Coefficient }\end{array}$ \\
\hline \multirow{2}{*}{ Hardening } & Ordinary cement, grass planting brick, water \\
permeable brick & 0.74 \\
\cline { 2 - 3 } & Asphalt & 0.88 \\
\hline \multirow{2}{*}{$\begin{array}{c}\text { Greening and water } \\
\text { body }\end{array}$} & Green space & 0.79 \\
\cline { 2 - 3 } & Water surface & 0.96 \\
\hline
\end{tabular}

\subsection{Preparation of Schemes for Planned Scenarios}

Six schemes for planned scenarios are prepared (see Table 3), and CTTC model is utilized to calculate the thermal environment for these schemes. Each scheme is prepared as follows: set plot ratio 2.0 , building density $30 \%$ and green space rate $30 \%$, employ the basic model with striped cluster layout, equal building height, no open ground-floor space, and 2 trees $/ 100 \mathrm{~m}^{2}$ green space, and then adjust building layout, building height, open ground-floor space, greening and tree allocation to form 5 schemes (Fig. 1, Fig. 2, Fig. 3, Fig. 4, Fig. 5, and Fig. 6) for these scenarios while the plot ratio of 2.0 remains unchanged. All these schemes cause the variation of 16 indicators in the CTTC model (Table 4). 
Table 3. Parameters in the schemes for planned scenarios

\begin{tabular}{|c|c|c|c|c|c|}
\hline Scheme & $\begin{array}{c}\text { Building } \\
\text { Layout }\end{array}$ & $\begin{array}{c}\text { Building } \\
\text { Height }\end{array}$ & $\begin{array}{c}\text { Open Ground- } \\
\text { floor Space }\end{array}$ & $\begin{array}{c}\text { Green Space } \\
\text { Rate }\end{array}$ & Tree Rate \\
\hline Scheme 1 (basic model) & $\begin{array}{c}\text { Striped } \\
\text { cluster }\end{array}$ & Equal & No & $30 \%$ & $\begin{array}{c}2 / 100 \mathrm{~m}^{2} \text { green } \\
\text { space }\end{array}$ \\
\hline Scheme 2 (point layout) & Point cluster & Equal & No & $30 \%$ & $\begin{array}{c}2 / 100 \mathrm{~m}^{2} \text { green } \\
\text { space }\end{array}$ \\
\hline $\begin{array}{c}\text { Scheme 3 (south low } \\
\text { north high) }\end{array}$ & $\begin{array}{c}\text { Striped } \\
\text { cluster }\end{array}$ & $\begin{array}{c}\text { South low } \\
\text { north high }\end{array}$ & Yes & $30 \%$ & $\begin{array}{c}2 / 100 \mathrm{~m}^{2} \text { green } \\
\text { space }\end{array}$ \\
\hline $\begin{array}{c}\text { Scheme 4 (open ground- } \\
\text { floor space) }\end{array}$ & $\begin{array}{c}\text { Striped } \\
\text { cluster } \\
\text { space }\end{array}$ \\
\hline $\begin{array}{c}\text { Scheme 5 (high green } \\
\text { space rate) }\end{array}$ & $\begin{array}{c}\text { Striped } \\
\text { cluster }\end{array}$ & Equal & No & $40 \%$ & $\begin{array}{c}2 / 100 \mathrm{~m}^{2} \text { green } \\
\text { space }\end{array}$ \\
\hline Scheme 6 (high tree rate) & $\begin{array}{c}\text { Striped } \\
\text { cluster }\end{array}$ & Equal & No & $30 \%$ & $\begin{array}{c}4 / 100 \mathrm{~m}^{2} \text { green } \\
\text { space }\end{array}$ \\
\hline
\end{tabular}

Table 4. Schedule of variations in main parameters of CTTC model for six schemes

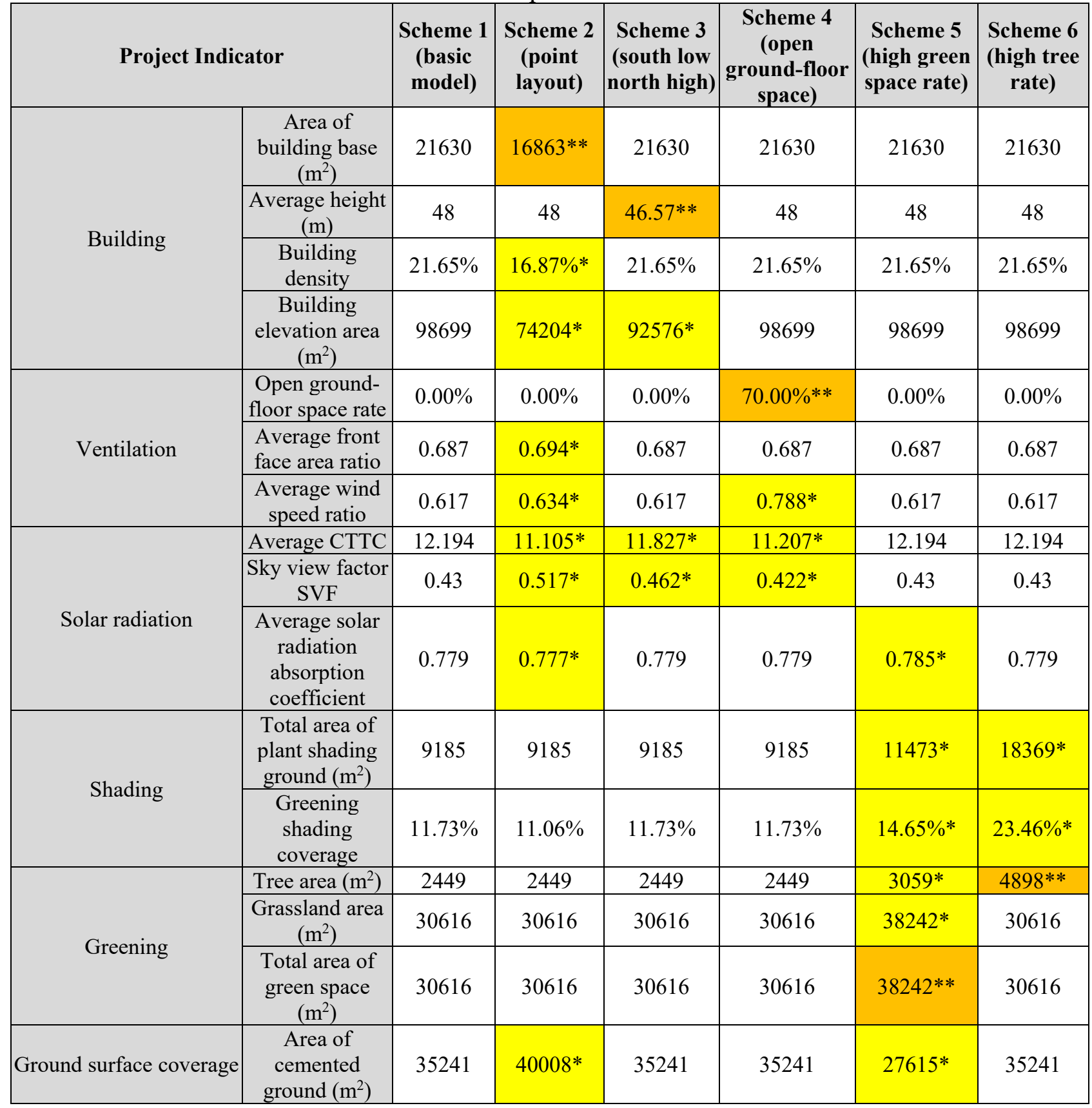

Note: "**" indicates the key indicator that varies in the scheme; "*" indicates the indicator that is changed due to the variation of key indicator. 


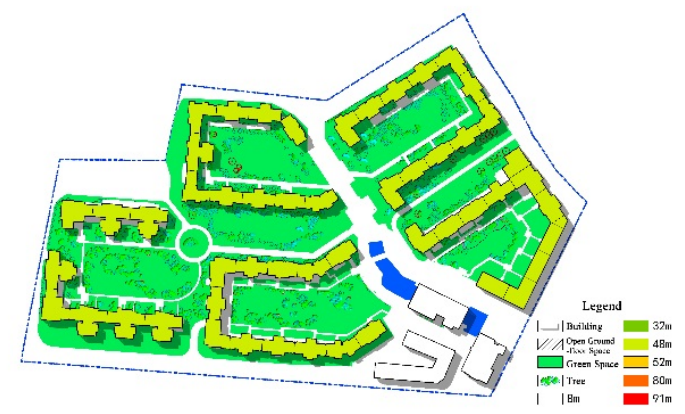

Fig 1. Scheme 1 (basic model)

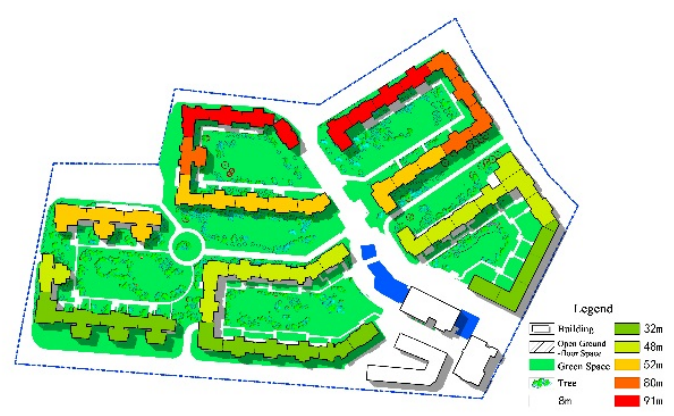

Fig 3. Scheme 3 (south low north tall)

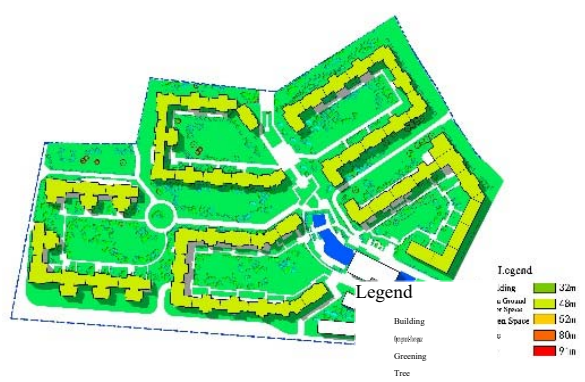

Fig 5. Scheme 5 (high green space rate)

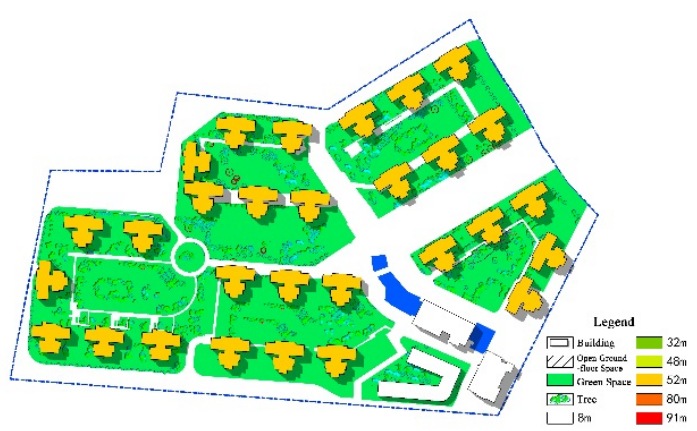

Fig 2. Scheme 2 (point layout)

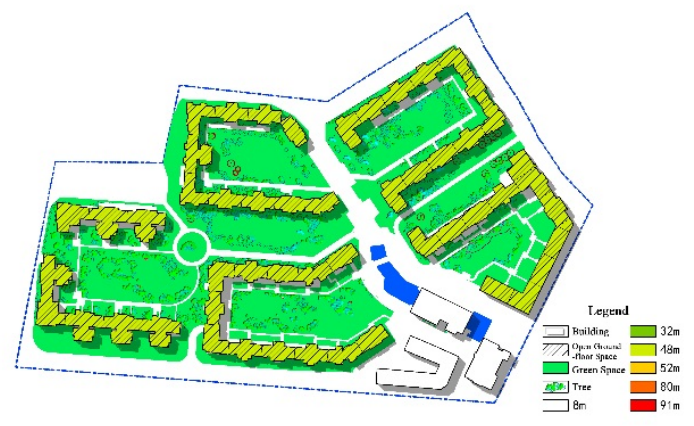

Fig 4. Scheme 4 (open ground-floor space)

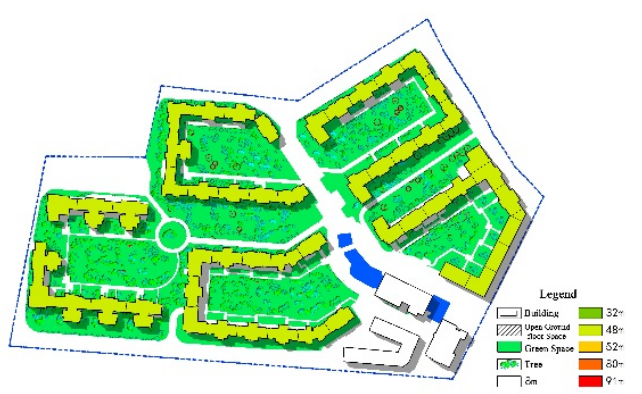

Fig 6. Scheme 6 (high tree rate)

\section{Analysis on Influence of Planning Design on Thermal Environment}

\subsection{Results of Thermal Environment Simulation}

As revealed in the simulation results, (1) the intensity of heat island in the day reveals that Scheme 2 (point layout) $>$ Scheme 3 (south low north high) $>$ Scheme 1 (basic model) $>$ Scheme 4 (open ground-floor space) $>$ Scheme 5 (high green space rate) $>$ Scheme 6 (high tree rate) (Fig. 7); (2) heat island peaks at 23:00 and hits the bottom at 10:00, and cold island effect occurs between 8:00 and 12:00. The results are obtained for the following reasons: 1 . The residential community is affected by the shadow of buildings, so its temperature rises more slowly than that in the suburb; 2 . The residential community has a lower SVF, which slows down the outward heat dissipation by long-wave radiation at night; 3 . The residential community has a lower wind speed than the suburb, causing slower heat dissipation (Fig. 8). 


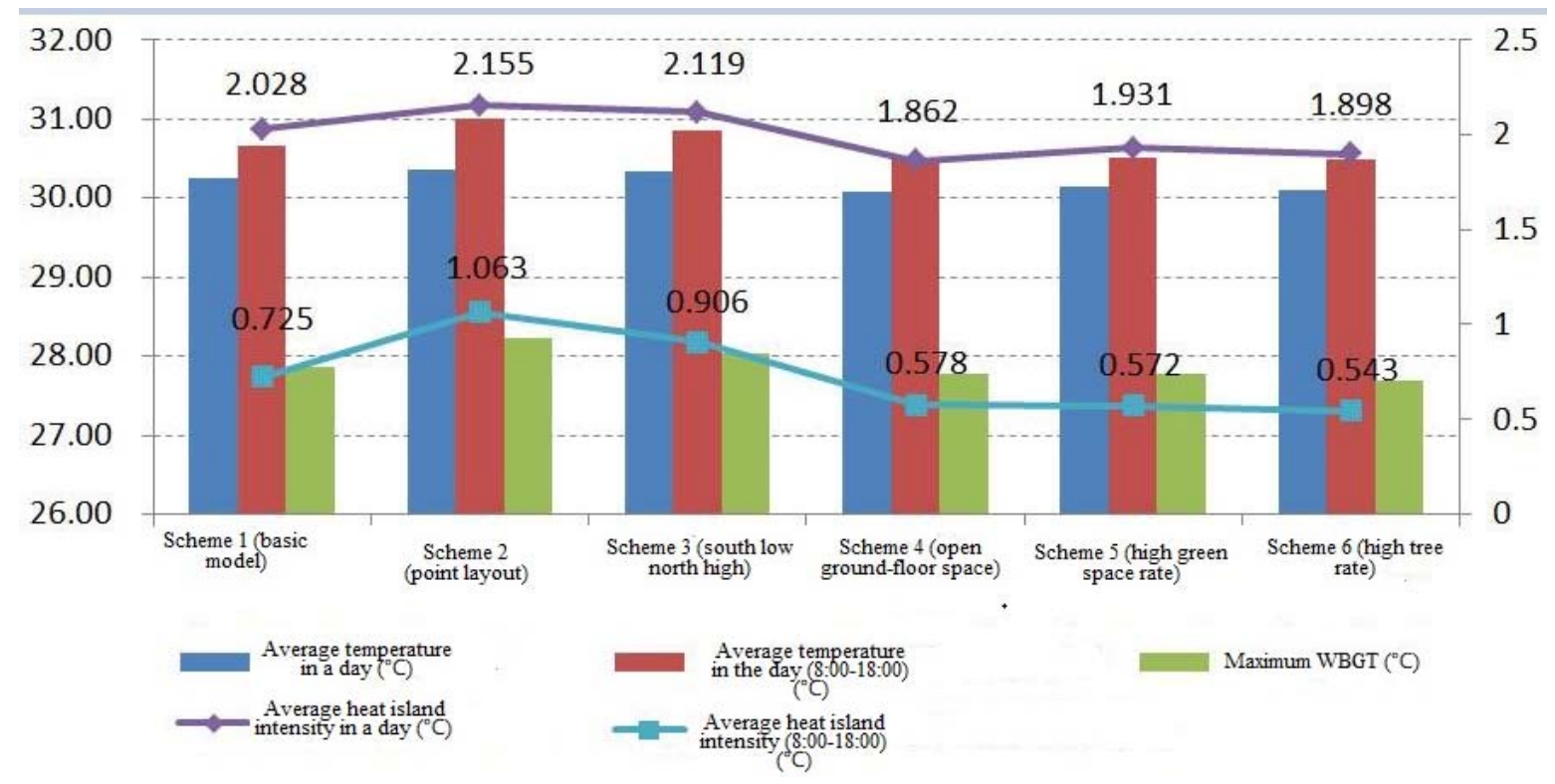

Fig 7. Simulation results of thermal environment in six schemes

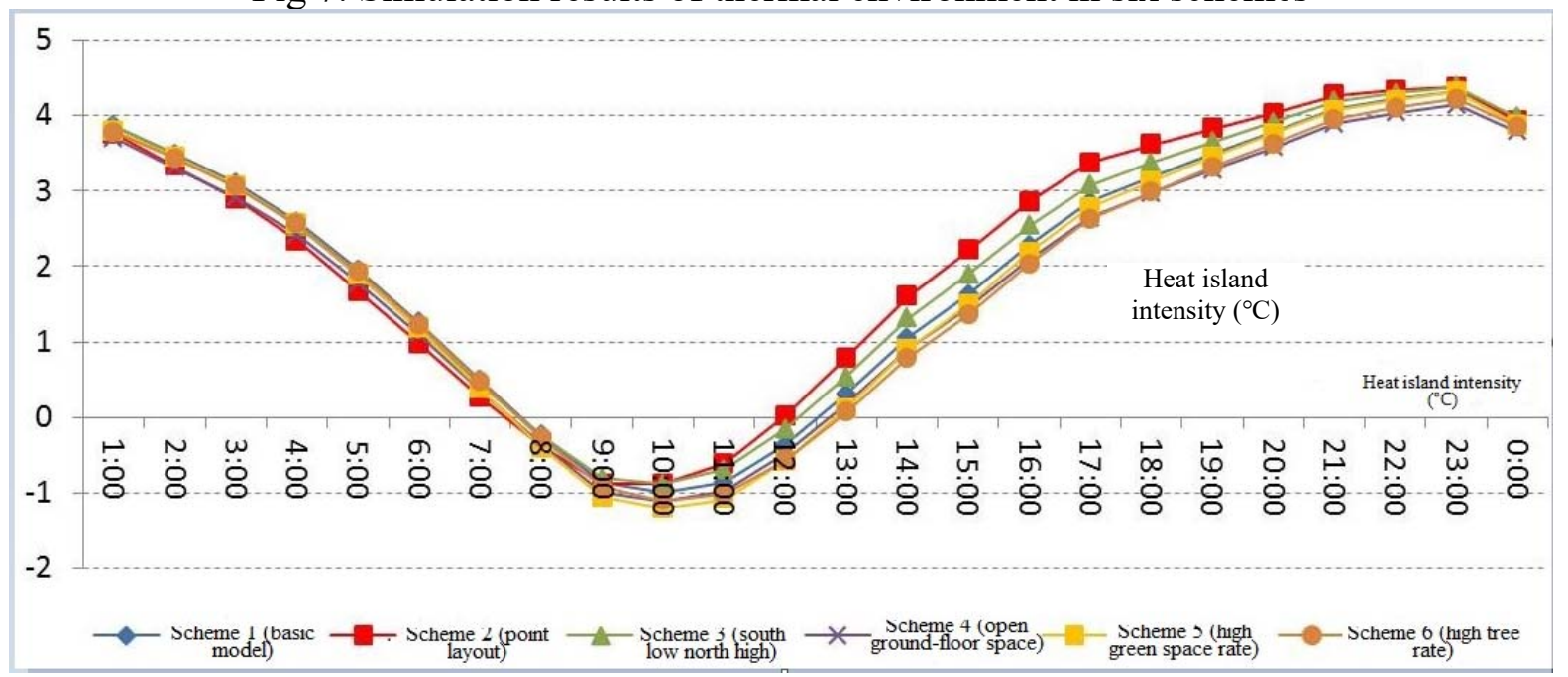

Fig 8. Hourly simulation results of heat island intensity for six schemes

\subsection{Influence of Building Layout}

As revealed in the comparison of six schemes, Scheme 2 (point layout) has the highest heat island intensity. Compared to Scheme 1 (basic model), it is $0.127^{\circ} \mathrm{C}$ higher for average heat island intensity in a day, with WBGT $0.384^{\circ} \mathrm{C}$ higher, and $0.338^{\circ} \mathrm{C}$ higher for average heat island intensity in the day (8:00-18:00), with WBGT $0.384^{\circ} \mathrm{C}$ higher. As shown in the parameters of CTTC model, the point cluster layout causes the variation of 9 indicators including area of building base, building elevation area, average wind speed ratio, and sky view factor, compared to the striped cluster layout. The analysis reveals that striped cluster layout realizes a more encircled arrangement of buildings, so more shadow of buildings is created to achieve lower incidence of solar radiation than point cluster layout, so it helps achieve lower temperature and heat island intensity (Fig. 7).

\subsection{Influence of Building Height}

Scheme 3 (south low north high) has the second highest heat island intensity. Compared to Scheme 1 (basic model), it is $0.091^{\circ} \mathrm{C}$ higher for average heat island intensity in a day, with WBGT $0.062^{\circ} \mathrm{C}$ higher, and $0.181{ }^{\circ} \mathrm{C}$ higher for average heat island intensity in the day (8:00-18:00), with WBGT $0.122^{\circ} \mathrm{C}$ higher. As for the parameters of CTTC model, Scheme 3 causes the variation of 4 indicators including average building height, building elevation area, average CTTC, and sky view factor. As found in the analysis, the building height arrangement of south low north high makes the residential community more open in the south, which results in higher incidence of solar radiation than equal building height, so the temperature in this scheme is higher than Scheme 1 (basic model) (Fig. 7). 


\subsection{Influence of Open Ground-floor Space}

In Scheme 4 (open ground-floor space), the heat island intensity in a day is $1.862^{\circ} \mathrm{C}$, which is the lowest value among six schemes. Compared to Scheme 1 (basic model), it is $-0.165^{\circ} \mathrm{C}$ lower for average heat island intensity in a day, with WBGT $-0.082^{\circ} \mathrm{C}$ lower. Among the parameters of CTTC model, 4 indicators are changed in Scheme 4, i.e. open ground-floor space rate, average wind speed ratio, sky view factor, and average CTTC. Among them, average wind speed ratio is increased from 0.617 to 0.788 , which is a significant variation. In other words, the design of open ground-floor space can effectively improve the wind environment in a scheme, and speed up the heat dissipation of residential area, which lowers the average temperature and heat island intensity in the scheme (Fig. 7).

\subsection{Influence of Greening}

Compared to Scheme 1 (basic model), Scheme 5 (high green space rate) is $-0.096^{\circ} \mathrm{C}$ lower for average heat island intensity in a day, with WBGT $-0.048^{\circ} \mathrm{C}$ lower. Among the parameters of CTTC model, Scheme 5 causes the variation of 7 indicators including average solar radiation absorption coefficient, greening shading coverage, and total area of green space. On one hand, the gardening plants in green space can convert solar energy into chemical energy through photosynthesis to reduce the heat dissipated into the environment. On the other hand, these plants can constantly absorb the heat from the environment through transpiration to lower the ambient temperature (Fig. 7).

Scheme 6 (high tree rate) has the lowest heat island intensity in the day. Compared to Scheme 1 (basic model), it is $-0.130^{\circ} \mathrm{C}$ lower for average heat island intensity in a day, with WBGT $-0.072^{\circ} \mathrm{C}$ lower, and $-0.183^{\circ} \mathrm{C}$ lower for average heat island intensity in the day, with WBGT $-0.108^{\circ} \mathrm{C}$ lower. Among the parameters of CTTC model, Scheme 6 experiences the change of 3 indicators, namely total area of plant shading ground, greening shading coverage, and tree area. The change must be caused for the following reasons: 1 . Trees have high heat capacity, so their temperature rises very slowly after being exposed to solar radiation, which can help stabilize the thermal environment of residential community; 2 . Trees have high leaf area index, which can effectively reduce the incidence of solar radiation; 3 . Trees have stronger transpiration to better lower the ambient temperature (Fig. 7).

\section{Development of Thermal Environment Regulation Strategies and Optimized Scheme}

\subsection{Design Strategies for Thermal Environment Regulation}

As shown in the above study, 10 design strategies for thermal environment regulation are developed in terms of building layout and design, greening design, paving and shading design (Fig. 9).

Fig. 9 Technical framework for thermal environment regulation of a residential community

All buildings in the residential community satisfy the requirements for green buildings with two stars or more. In the residential community, 4 out of 5 clusters have their buildings satisfying the above requirements, and 1 cluster has its buildings meeting the requirements for green buildings with three stars. All buildings in the residential community achieve the energy saving rate of more than $50 \%$. The lowered energy consumption of buildings can reduce the heat dissipation and improve the thermal environment (Fig. 10).

The southeast-northwest wind corridors are formed to improve the environmental ventilation of the residential community. In summer, southeast wind prevails in Guangzhou, so it is designed to have the main access in the southeast of the residential community and locate its public buildings in the southeast as well. Moreover, southeast-northwest wind corridors are planned to make the wind blow into the residential community (Fig. 11).

Building height increases gradually from the middle to both sides, so as to guarantee the effectiveness of wind corridors in the middle. Starting from the wind corridors in the middle of the residential community, building height gradually increases on both sides to improve the openness of green space in the middle while maintaining the plot ratio. Meanwhile, this can also lower the wind resistance of wind corridors and enhance the efficiency of ventilation (Fig. 12). The variation of building height can also help guide the wind from the height to the ground surface (Fig. 13). 


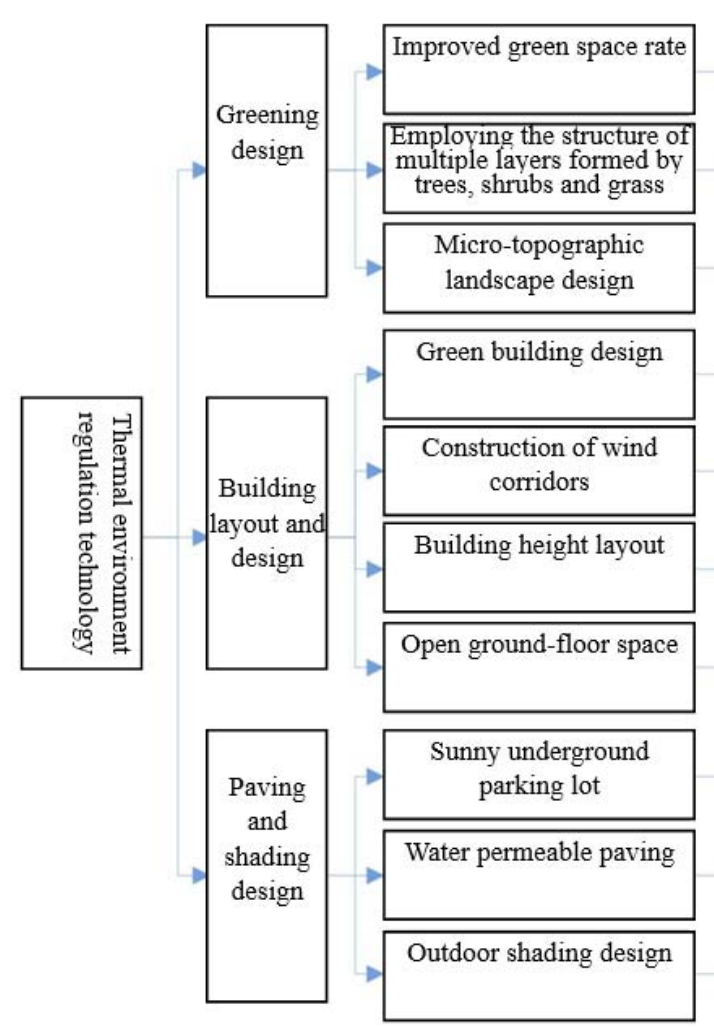

The planned green space rate is increased from $30 \%$ to $40 \%$. Idesign combining trees, shrubs and grass is employed to improve the green space rate.

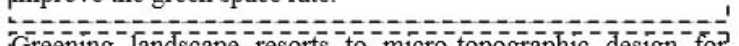
higher soil capacity and permeable surface area, so as tol facilitate the formation of local breeze.

(1)

iAlr building ss of the ${ }^{-}$residential ${ }^{-}$community ${ }^{-}$satisfy ${ }^{-}$the requirements for green buildings with two stars or more.

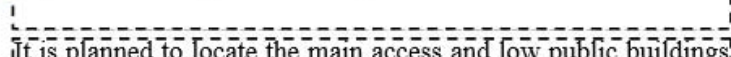

lit is planned to aate the man access and ,corridors to make wind blow into the residential community.

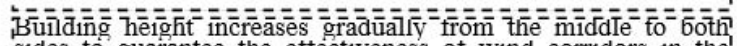
isides to guarantee the eftectiveness ot wind corridors in the middle and community downwards.

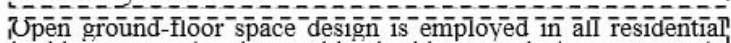
ibuildings except a tew public buildings and stores, so as to effectively improve the wind environment at the height of 'pedestrians.

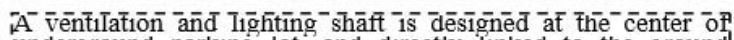
underground parking lot, and directly linked to the ground the parking lot and tacilitate the air convection.

AAlr roads inside the residential communty empo the water permeable paving to reduce the large impermeable ground asi much as possible.

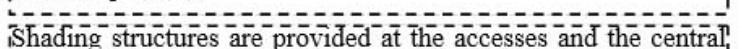

area of the residential community and each cluster to improve,

the comfort for residents during outdoor activities in summer.

Fig 9. Technical framework for thermal environment regulation of a residential community
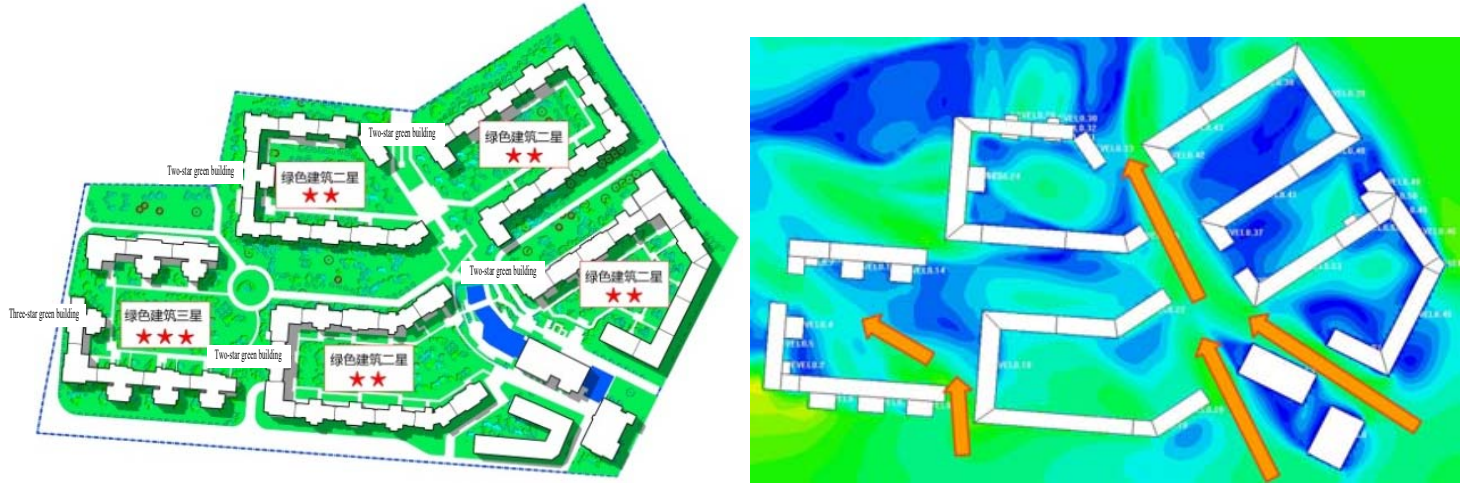

Fig 10. Layout plan of green buildings with stars Fig 11. Layout plan of ventilation corridors

Open ground-floor space facilitates ventilation. The open ground-floor space design is utilized in all residential buildings except a few public buildings and stores. As indicated in the CFD simulation analysis, open ground-floor space can considerably improve the wind environment of the residential community and enhance the wind speed by $15 \% \sim 30 \%$ (Fig. 13).

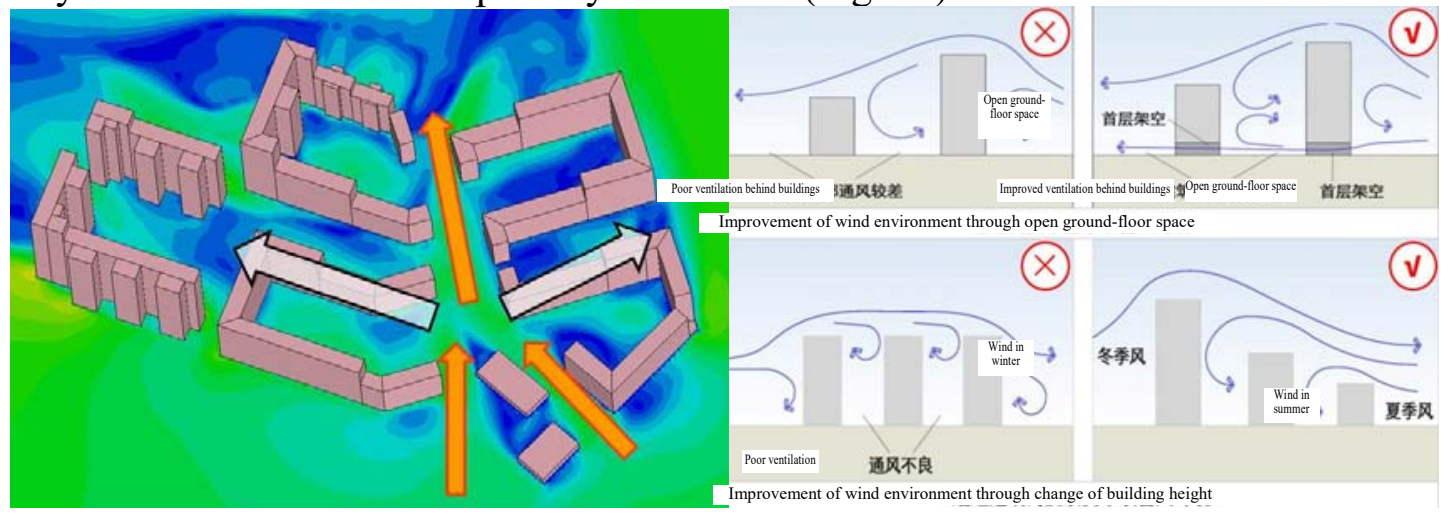

Fig 12. Schematic diagram of building height plan

Fig 13. Open ground-floor space and height design 
Green space rate is increased. The planned green space rate is increased from the required $30 \%$ to $40 \%$, and the per capita area of public green space is increased from $1 \mathrm{~m}^{2} /$ person to $1.89 \mathrm{~m}^{2} /$ person. Moreover, the surface temperature of green space is measured using the thermal infrared imaging technology. It is known that the surface temperature of greening ground is $2 \sim 5^{\circ} \mathrm{C}$ lower than the hardened ground.

Greening is achieved with multiple layers formed by trees, shrubs and grass. The planned tree rate is $4.3 / 100 \mathrm{~m}^{2}$ green space. Through thermal infrared imaging analysis, it is found that different types of plant can lower the temperature to different degrees. On the whole, trees and shrubs can lower the temperature better than herbaceous plants and achieve stronger efficiency of temperature reduction in the day [13].
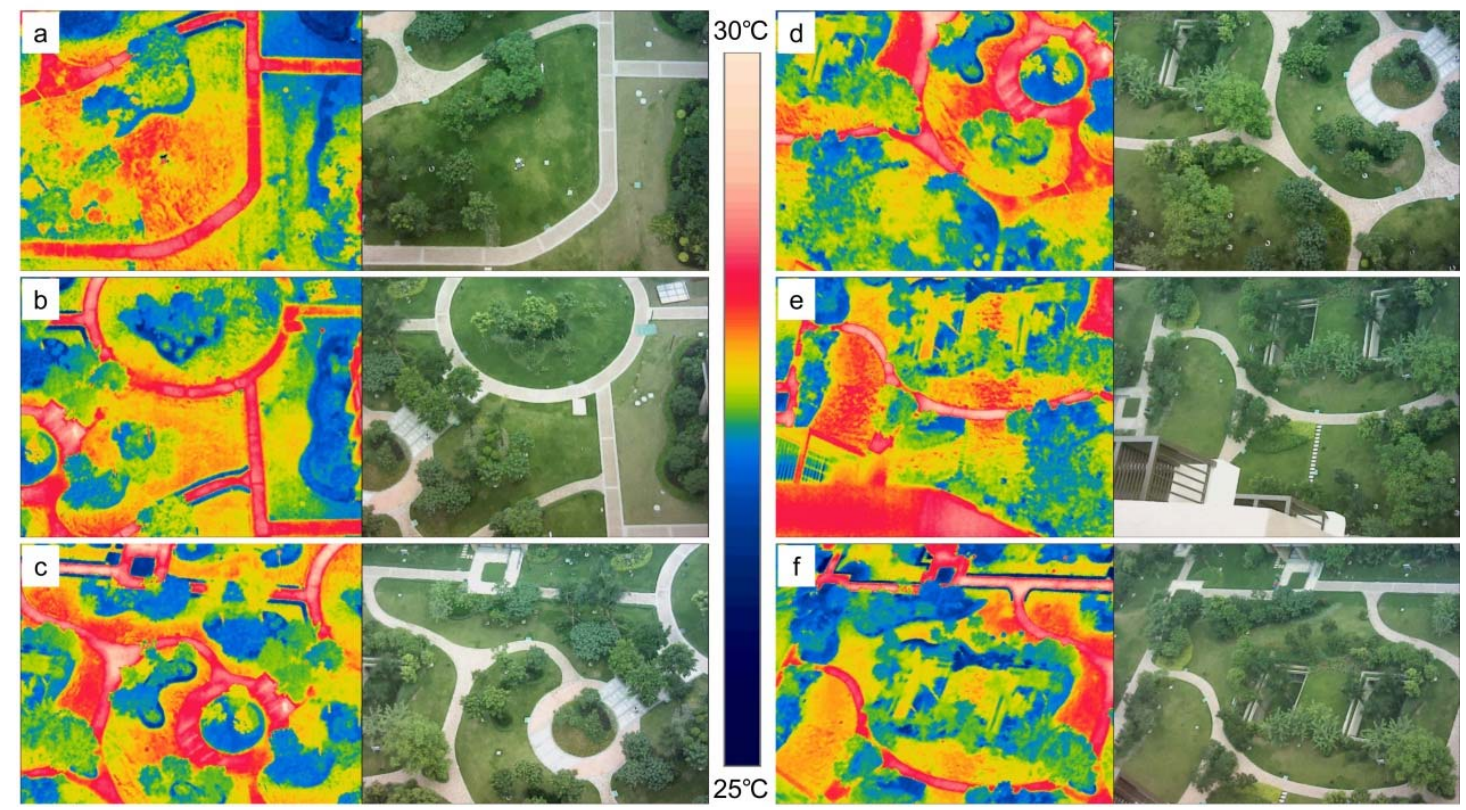

Fig 14. Thermal imaging of green space at 8:00a.m.

Micro-topographic design is employed (Fig. 15). Micro-topography can help increase the surface area of green space; increase the soil capacity to facilitate collection of rainwater and improve evaporation; and promote the near-surface airflow through the temperature difference between the side facing the sun and the shadowed side.

Sunny underground parking lot is designed (Fig. 16). Due to the large temperature difference between garage and green space at the center of a cluster, the air of upper and lower layers forms the convection to resolve the ventilation problem for parking lot and improve the local microclimate.

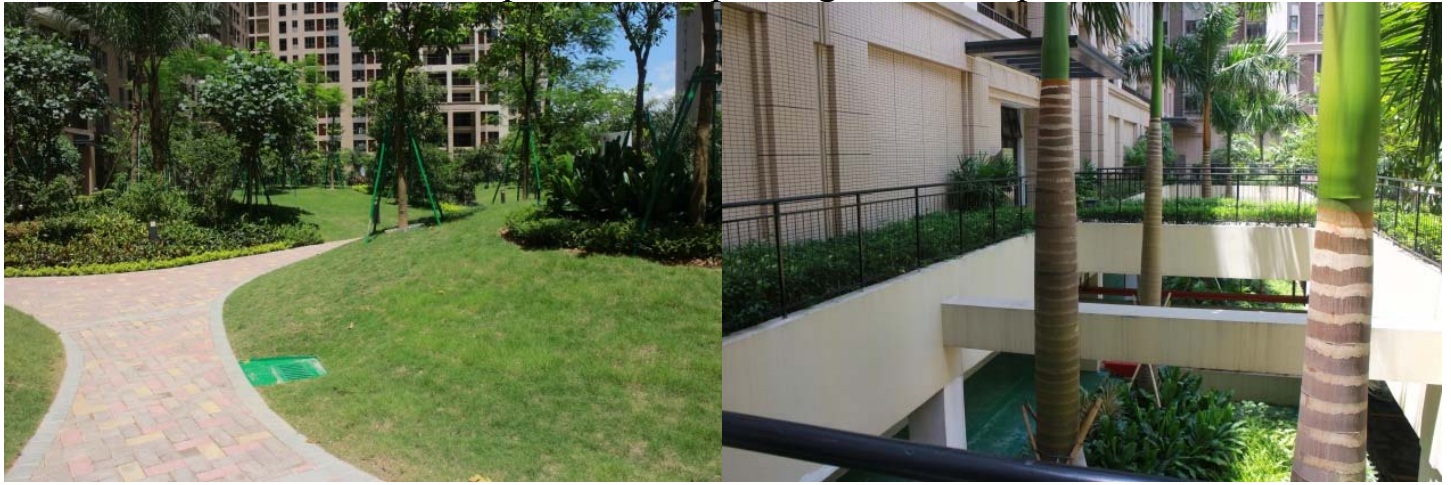

Fig 15. Photo of micro-topographic design Fig 16. Photo of sunny underground parking lot

All roads inside the residential community are provided with water permeable paving. As revealed in the study by Ao Jing [14], water permeable paving can effectively improve the thermal environment of the residential community. Along with the increase of water permeable underlying surface coverage, outdoor temperature is gradually lowered.

Shading structures are provided in the residential community and at the access and central area of each cluster to improve the comfort of residents during outdoor activities. The studies conducted by 
Liu Jing [15] and other scholars reveal that a 1\% increase of shading coverage can lower the heat island intensity by $0.025^{\circ} \mathrm{C}$, and it is believed that if shading coverage is adjusted to $10 \% \sim 20 \%$, the heat island intensity of the residential community will be lower than $1.5^{\circ} \mathrm{C}$.

\subsection{Development of Optimized Scheme and Its Thermal Environment Simulation Evaluation}

After adopting the 10 design strategies for thermal environment regulation, a thermal environment simulation is carried out for CTTC model (Fig. 17). The results show that: (1) the optimized scheme realizes the average heat island intensity in the day $0.344^{\circ} \mathrm{Cwith}$ maximum WBGT in a day $27.611^{\circ} \mathrm{C}$, which satisfy the requirements of the Design Standard for Thermal Environment of Urban Residential Areas (JGJ286-2013) for the average heat island intensity in the day $<=1.5^{\circ} \mathrm{C}$, with maximum WBGT in a day $<=33^{\circ} \mathrm{C}$; (2) the optimized scheme achieves the average temperature in a day $29.9^{\circ} \mathrm{C}$, the average heat island intensity in a day $1.687^{\circ} \mathrm{C}$, and the average temperature in the day $30.28^{\circ} \mathrm{C}$. Hence, all these indicators are lower than those in six schemes for various scenarios. In other words, the design strategies for thermal environment regulation have greatly improved the thermal environment of the residential community.

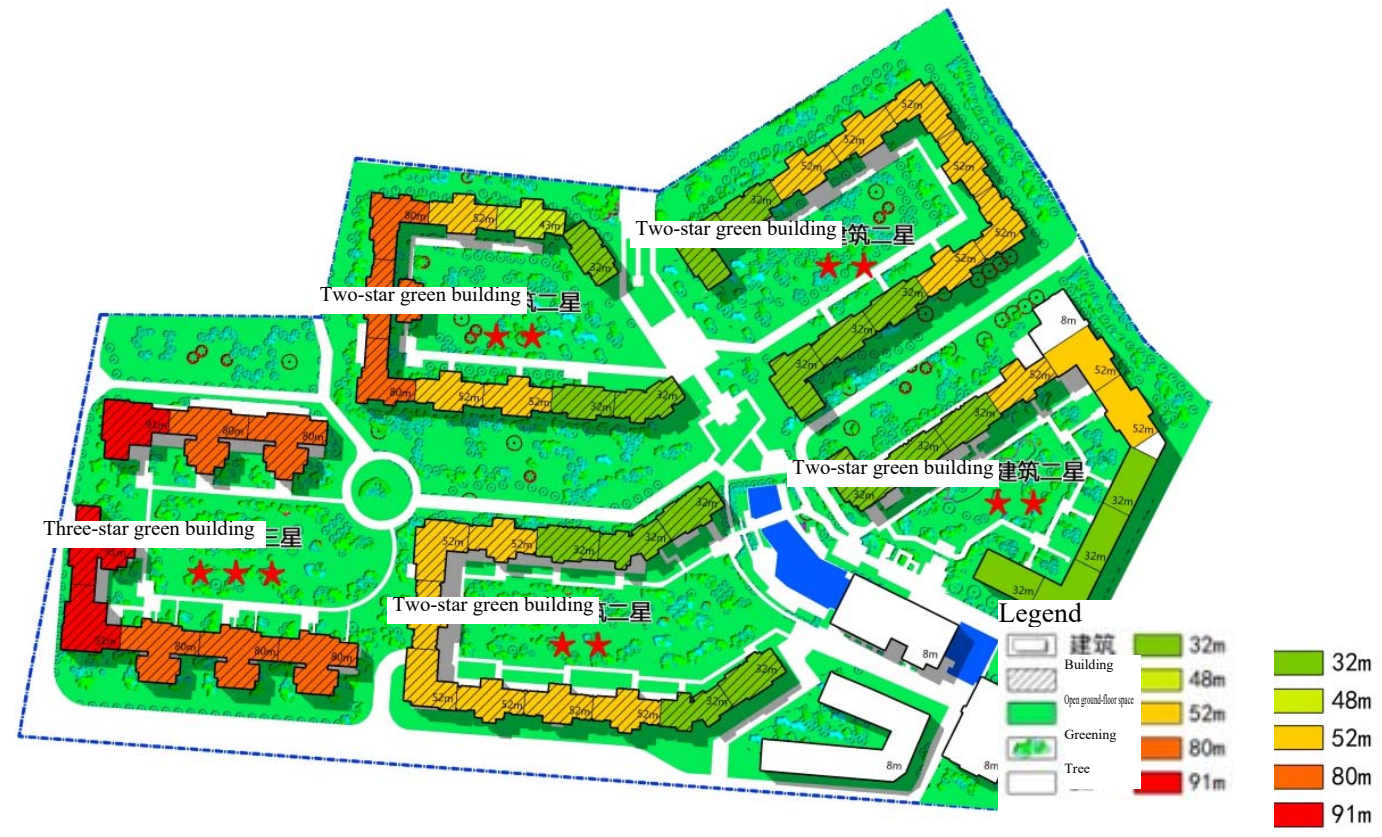

Fig 17. Schematic diagram of optimized scheme planning

\section{Conclusion}

Above all, the following conclusions are drawn: (1) the thermal environment of the residential community can be most effectively improved by employing open ground-floor space, enhancing green space rate, and increasing the number of trees; (2) in terms of the effective reduction of heat island intensity in the day, five strategies are arranged in the following sequence: increasing number of trees $>$ enhancing green space rate $>$ employing open ground-floor space $>$ utilizing building layout of south low north high $>$ select point layout of buildings; (3) point layout of buildings can improve the wind environment of the residential community, but it increases the incidence of solar radiation, which enhances the heat island intensity correspondingly; (4) 10 design strategies for thermal environment regulation are developed in terms of building layout and design, greening design, paving and shading design, so as to effectively improve the thermal environment of residential community and lower the intensity of heat island.

\section{Acknowledgments}

Project of the National Natural Science Foundation of China: Study on evaluation model and design method of urban thermal environment for regulatory plan in hot and humid 
regions(ID:51778236); Guangzhou Science and Technology Project: Research on microclimate Simulation Model and Regulation Technology for Urban Renewal of Guangzhou (ID: [2016]172).

\section{References}

[1]. Xiao R.B., Ouyang Z.Y., Zhang Z.M. et al. Advances in methodology of urban heat island [J]. Meteorological Monthly, 2005,31(11):3-6.

[2]. Summers, P.W. An urban heat island model--its role in air pollution problems, with application to Montreal. First Canadian Conf. on Micrometeorology, Toronto, ON, Canada,1965.

[3]. Kusaka H, Kondo H, Kikegawa $\mathrm{Y}$, et al. A simple single-layer urban canopy model for atmospheric models: Comparison with multi-layer and slab models[J]. Boundary-Layer Meteorology, 2001,101(3): 329-358.

[4]. Swaid H, Hoffman M E. Prediction of urban air temperature variations using the analytical CTTC model[J]. Energy and Buildings. 1990, 14(4): 313-324.

[5]. Shu L.F., Meng Q.L., Zhang L. et al. Study on improvement of street canyons air temperature predication model [J]. Acta Energiae Solaris Sinic, 2010, 31(12):1622-1627.

[6]. Chen J.M. Development of Calculation Program for Thermal Environment of Residential Community Based on Lumped Capacity [D]. South China University of Technology, 2010.

[7]. Zhang Y.F., Wang, Z.G., Sun Y.X. Analysis of Urban Heat Island Effect Using an Improved CTTC and STTC Model [J]. Transactions of Tianjin University, 2009, 15(03): 201-205.

[8]. Lin B.R., Li Y., Zhao B. et al. Predicting and evaluating the residential outdoor thermal environment in the design of urban environment [J]. Urban Environment \& Urban Ecology, 2002, (01):41-43.

[9]. Liu D.L. Empirical Test and Research of CTTC Model [D]. South China University of Technology, 2013.

[10]. Sun Y.X., Lu J.J., Dong W.Z. et al. Urban heat island analysis based on CTTC and STTC models [J]. Gas \& Heat, 2005, (05):11-17.

[11]. Liang H.Y., Li X.H. and He L.J. City-scale zoning method to improve thermal environment of Guangzhou [J]. Urban Planning Forum, 2013, 7:107-113.

[12]. Nie W.X., Li X.H. and Liang H.Y. Cooling Effects of Greening in a Typical Residential Area in Guangzhou [J]. Guangdong Landscape Architecture, 2016, 38(02):73-77.

[13]. Ao J. The Effect of Urban Permeable Pavement System on Local Thermal and Moisture Environment [D]. Harbin Institute of Technology, 2014.

[14]. Liu J. Research of Outdoor Environment Shading's Effects on the Thermal Environments in Residential District [D]. South China University of Technology, 2012. 